Peer-Reviewed Article
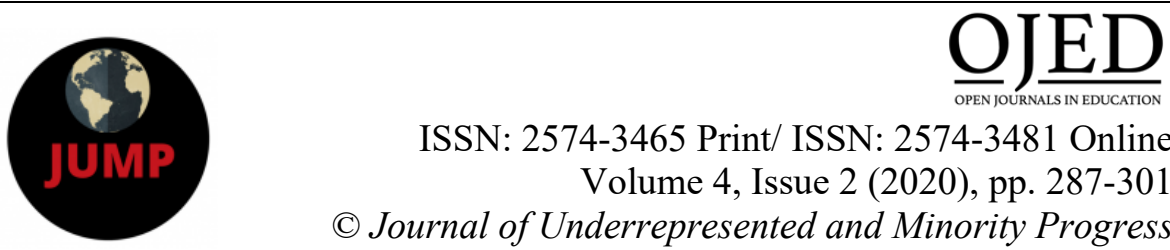

ISSN: 2574-3465 Print/ ISSN: 2574-3481 Online

Volume 4, Issue 2 (2020), pp. 287-301

(C) Journal of Underrepresented and Minority Progress

http://ojed.org/jump

\title{
Fishing Community in Wetland Region of Bangladesh: Views from the Field Experiences of Hakaluki Haor
}

\author{
Mohammad Ali Oakkas \\ Shahjalal University of Science \& Technology, Bangladesh \\ Md. Fakrul Islam \\ University of Rajshahi, Bangladesh
}

\begin{abstract}
This study is a part of doctoral dissertation which basically observes the socio-economic condition of the artisanal fishing community of Hakaluki Haor in Bangladesh. The original study is exploratory in nature, and both qualitative and quantitative approaches have been used to attain the goals and objectives of the study. The main objective of the current article is to identify the present socio-demographic background of Hoar fishing community in Bangladesh. Data analysis has focused on the actual situation of the household of fishing community from the Haor perspective. The findings of the study have been categorized on the basis of five capitals (i.e., social, human, physical, financial and natural resources) that structure the conceptual framework of the study. It is shown that most of the fishing community in the Haor basin are living under the most unpleasant and vulnerable conditions in terms of income, food security, housing patterns, health and sanitation conditions. Other issues center around child marriage, family planning, and social relations among the dwellers of the community. Also, among the observed problems are decision making, power practice, participation in development activities, socio-economic position in education and local institutions.
\end{abstract}

Keywords: Artisanal; Bangladesh; Hakaluki Haor; Haor; Resources; Wetlands 


\section{INTRODUCTION}

Hakaluki Haor is the largest eco-based water body in Bangladesh and has the largest wetland resources of Bangladesh and Asia, lying between the latitude $24^{\circ} 35^{\prime} \mathrm{N}$ to $24^{\circ} 45^{\prime} \mathrm{N}$ and longitude $92^{\circ} 00^{\prime} \mathrm{E}$ to $92^{\circ} 08^{\prime} \mathrm{E}$ (Uddin et al.,2013). The haor consists of Baralekha, Kulaura and Juri Upazilla under Moulvibazar District and Golapganj and Fenchuganj Upazilla under Sylhet District, which covers eleven Unions (Yeasmin,2012,21) Diversified land position, ecological variation and periodic atmospheres, delightful and delicious fish species are the beautiful resources of Hakaluki Haor. It is bordered by the Kulaura-Beanibazar road to the east, south and west side bounded by the Fenchuganj-Kulaura railway and Kushiara rivers to the north with a land area of 18,386 hectares (IUCN ${ }^{1}$, 2006,1). Uniquely, lands of Hakaluki can be classified under three specified segments: agricultural land, beel ${ }^{2}$ and khanda $^{3}$ (Islam et al., 2011, 948). Hakaluki Haor as an 'Ecologically Critical Area (ECA)'under the provision of Environmental Conservation Act, 1995 of Bangladesh (Banglapedia,2012).

Most of the inhabitants are fully dependent on haor resources. Fishing community of haor areas in Bangladesh earn their livelihood from haor assets such as fishing, agriculture, fuel wood collection, reeds and aquatic fruits. Therefore, haor plays a significant role in the lives of haor fishing community by providing sustainable livelihood options. In fact, haor fishing community are more vulnerable and marginalized in comparison to people living in the plain land of Bangladesh. There are many factors that are associated with the present state of haor fishing community. Some of them include scarcity of fish, overfishing, political influence on water body, tyranny of middlemen, lack of proper knowledge about fishing, lack of free access to open water body, illegal fishing, insufficient fishing equipment, absence of ownership of boats, rapid decrease of aquatic fruits, use of chemicals in agriculture, landlessness, seasonal unemployment, temporary migration, natural calamities, village and homestead erosion, flash flood, prejudice, ritual and beliefs.

${ }^{1}$ International Union for Conservation of Nature

${ }^{2}$ Beel: Beels are shallow lakes, which form the deepest parts of the haor.

${ }^{3}$ Each beel has surrounding land area and it is higher than the haor basin but lower than the homestead land known as khanda. This land is the government property, which people commonly use for the purpose of raising cattle and buffalo, duck and collecting firewood. 


\section{Research Questions}

The research questions that guide the current study are:

1. What is the socio-demographic situation of haor fishing community?

2. What are the major difficulties that haor fishing community face continuously?

3. Can local resources help overcome their situation?

\section{Study Objective}

The current study aims to:

1. Portray the present socio-demographic background of haor fishing community,

2. Identify the major difficulties, faced by the haor fishing community and analyze their experiences.

\section{REVIEW OF LITERATURE}

A comprehensive literature review has been conducted to have a total picture of the fishing community of Bangladesh. Only a few studies that directly address this topic have been found. The current study examines the socio-economic structure of fishing community and process of operating arrangement, to add onto the extant literature (e.g., Ali et al., 2014; Deb, 2009). Apart from focusing on the major difficulty in fish farming and fish marketing in the national and local level, the current study does not claim to significantly or directly contribute to the literature on the unavailability of fish and lack of technical training for the farmer and insufficient capital (Gill \& Motahar, 1982). In addition, in terms of microcredit, it has a limited impact on their livelihood development (Sultana $\&$ Thompson, 2007). The undertaken studies are different from each other in terms of sample size, locations of haor, time of data collection, variables, and methodologies. In attempt to fill up this gap in knowledge, the current study explores the undiscovered areas of haor fishing community, by investigating the facts and analyzing their condition.

\section{CONCEPTUAL FRAMEWORK}

Researchers view the Sustainable Livelihood Approach (SLA) as a comprehensive tool for reviewing livelihood options of marginalized groups of workers like fishing community, with a particular reference to the community in poverty. For this research, the SLA has been used as a tool for analyzing the situation of fishing community who are dependent on natural 
resources. We think that it is timely to use this approach to know their socioeconomic condition from a different perspective. In the theme of sustainable livelihood approach, the assets of fishing community can be categorized into five sections: natural, physical, human, financial and social capital. "Livelihood Platform" describes these assets in a snapshot of fishing communities.

For the purposes of creating our conceptual design, we refer to available natural resources in water bodies as natural capital. Fishing community in these areas are dependent on natural resources such as fish, vegetables, water, and land. In addition, physical capital includes physical structure of haor region like fishing equipment, embankment, communication, submerged road, boats, and nets that belong to haor people. As the central tenet of this framework, human capital is the most important assets. In haor region, the knowledge and skill of fishing community about fishing are the examined factors of this population. Financial capital also determines a phenomenon to analyze the livelihood of fishing community. In this context, assets, loan, cash, and ornaments are the basic resources. Lastly, social capital is a vital field to identify the socio-economic condition of people. For this reason, the present study has attempted to explore, identify and analyze the socio-economic condition of fishing community in the light of the SLA provided by the Department for International Development, which is directly related to lives of disadvantaged groups of people in haor basin of Bangladesh. Furthermore, it also analyzes the multidimensional nature and trends of poverty among the fishing community of this country. To this end, we see SLA as an appropriate lens to explore the real situation of fishing community of Hakaluki Haor of Bangladesh. Now it is under severe threats due to political and socio-economic perspective. From the above argument, the researchers have drawn a conceptual framework with the help of SLA in this study. 


\section{Figure 1}

Conceptual Framework (Developed by researcher)

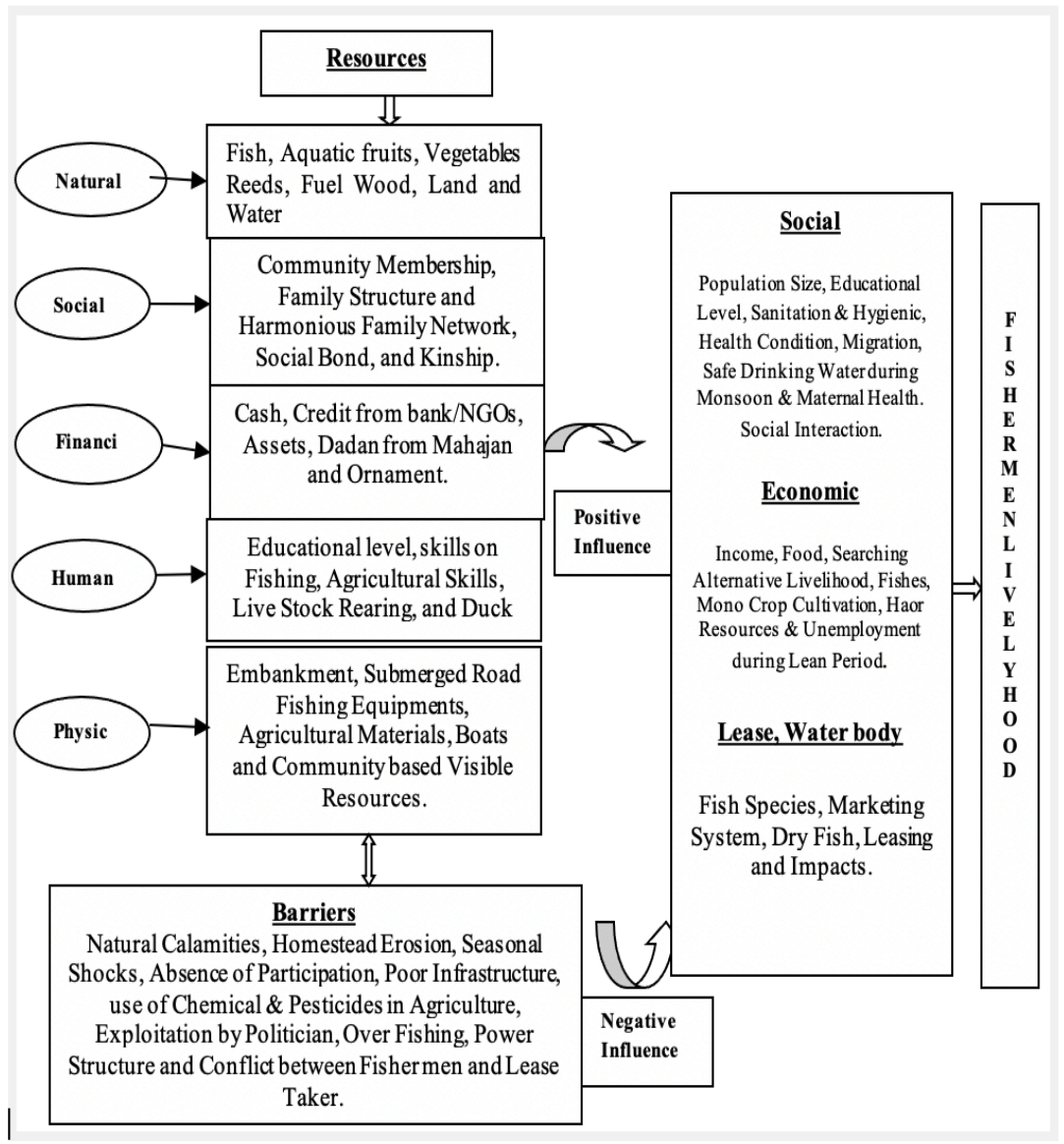

\section{RESEARCH METHODS}

We designed the study was to be exploratory in nature using qualitative and quantitative approaches to seek answers to the research questions. Hence, this is a mixed-methods study. Qualitative data has been collected from the participants using interview and observation. Open and close-ended questions in a survey format were used to collect quantitative data, which was analyzed by using the Statistical Package for the Social Sciences (SPSS) by IBM. Descriptive statistics have been used to analyze the obtained data. The researcher has used required graphs and charts to 
support the analysis of the data when necessary. Besides, researcher has collected field notes about the attitudes and perception of the respondents. Audio and video recorders have been used as tools for qualitative data collection after receiving the permission of the participants. Physical condition of respondents has also been observed as much as possible. The recorded interviews were transcribed for analysis. Data analyses have been done in an iterative process to attain a general understanding of the content.

Table 1

Demographic Profile of the Respondents in the Study Area

\begin{tabular}{|c|c|c|c|c|c|}
\hline Nature & Variables & Frequency & $\%$ & Total & $\begin{array}{c}\text { Mean (when } \\
\text { applicable) }\end{array}$ \\
\hline \multirow{3}{*}{$\begin{array}{l}\text { Religion of the } \\
\text { Respondents }\end{array}$} & Muslim & 240 & 83.6 & \multirow{3}{*}{$\begin{array}{l}5 \\
8 \\
8 \\
0\end{array}$} & \\
\hline & Hindu & 47 & 16.4 & & \\
\hline & Others & 0 & 0.0 & & \\
\hline \multirow{2}{*}{$\begin{array}{l}\text { Sex of the } \\
\text { Respondents }\end{array}$} & Male & 279 & 97.2 & \multirow{2}{*}{$\frac{8}{8}$} & \\
\hline & Female & 08 & 2.8 & & \\
\hline \multirow{4}{*}{ Marital Status } & Married & 269 & 93.7 & \multirow{4}{*}{$\begin{array}{l}3 \\
8 \\
\circ\end{array}$} & \\
\hline & Unmarried & 5 & 1.7 & & \\
\hline & Widow & 2 & 0.7 & & \\
\hline & Widower & 11 & 3.8 & & \\
\hline \multirow{5}{*}{ Education Level } & Illiterate & 70 & 24.4 & \multirow{5}{*}{$\frac{8}{8}$} & \\
\hline & Literate & 128 & 44.6 & & \\
\hline & Primary & 78 & 27.2 & & \\
\hline & $\mathrm{SSC}$ & 9 & 3.1 & & \\
\hline & $\mathrm{HSC}$ & 2 & 0.7 & & \\
\hline \multirow{3}{*}{ Size of Family } & Small 0-5 & 114 & 39.7 & \multirow{3}{*}{$\begin{array}{l}3 \\
8 \\
\circ\end{array}$} & \multirow{3}{*}{5.57} \\
\hline & $\underset{8}{\text { Medium } 6 \text { - }}$ & 121 & 42.2 & & \\
\hline & Large 8-10 & 52 & 18.1 & & \\
\hline \multirow{3}{*}{$\begin{array}{l}\text { Number of } \\
\text { Children per } \\
\text { Family }\end{array}$} & $1-3$ & 121 & 42.16 & \multirow{3}{*}{8} & \multirow{3}{*}{4.06} \\
\hline & $4-6$ & 135 & 47.04 & & \\
\hline & $7-9$ & 31 & 10.80 & & \\
\hline
\end{tabular}

(Source: Field Survey, July-December 2015)

\section{Participants}


Demographic profile is an important phenomenon to know the key features of the household respondents, as it clearly shows the status of social aspects of respective household. The demographic data indicates the respondents' identity on the basis of religious perspective, it reveals the marital status of the respondents in the study area. In this section, data also indicates educational level, size of the family, relationship patterns among the family members, association and festivals, number of children in family and social interaction among the societal people, health status, sanitation, housing and water.

\section{Human Capital}

\section{RESULTS}

Education is an important factor in analyzing the socio-demographic features of human being. It indicates that 44.6 percent, 3.1 percent, and 0.7 percent of the respondents have educational level up to literacy, SSC and HSC programs respectively. At the same time, almost one fourth $(24.4 \%)$ of the respondents are illiterate. The findings clearly show that the educational state of the haor locality is very low.

Size of family is an essential element to learn about the fishing community livelihood in the study area. It is found that 5.57 is the average number of the individuals in a household, which is higher than the national level. It also shows that the 42.2 percent of the households reside as a group that is under the medium size (6-8 persons) family structure. So, absence of family planning, improper education and lack of motivation are the major responsible factors behind the structure of family.

Marriage is a common social convention and celebration in Bangladesh. Almost 93.7 percent of the respondents are married in the study area. In addition, marital age is also a significant factor to determine the human capital of the fishing community household. Most of the respondents $(64.1 \%)$ have stated that most of the male persons usually get married in the age of 20-24 while 69.7 percent of the females get married under the age of 15-19.

The nature of the family type indicates the demographic profile of the respondents' households. It has been found that almost 91.3 percent fishing community families are nuclear or single type of family while only 7.0 percent respondents live as joint families. So, data clearly focus the increasing trend of the nuclear type of family in this area of Bangladesh.

Status for decision-making is an important phenomenon to understand the nature of empowerment in the household family. It has been 
exposed that most of the household head (58.2\%) take decisions by themselves and only 15 percent respondents take decisions by consulting with their spouses. So, decision making process is absolutely regulated by the male members of the family.

Dependent members of the families regulate the homestead activities, one of which is collection of the drinking water. It has been observed that about half of the respondents $(42.5 \%)$ have opined that water is collected by the aged female member of the family. At the same time, 33.8 percent of the interviewees have expressed that drinking water is collected by the children of the family. So, it can be said that the dependent portion of the family members are involved in activities related with water collection.

Family planning program is a vital way to control and minimize the growth of population in Bangladesh. In this study, the data speaks to the family planning related information in the haor region. It is evident that only 27.9 percent of the respondents received family planning method for population control while about one fifth $(18.8 \%)$ of the total users have followed a permanent family planning method. It indicates the scenario of family planning status in the fishing community.

The fishing community who do fishing in Hakaluki Haor can be categorized under three groups based on their involvement in fishing and fish processing related activities: full time, part time and subsistence. More than half of the respondents $(53.31 \%)$ are involved in full-time fishing and 17.42 percent of the households are involved in fish retailer. So, it can be said that the fishing and fish processing related activities are the bread and butter of the respondents' households.

As the basic need for human life, dwelling is the physical capital of the fishing community when the SLA is considered. Table 2 displays the dwelling scenario of haor household fishing community. Data indicates that 38.68 percent of the interviewees' dwelling status is flimsy and 32.75 percent has dwelling status in congestion and danger. 13.94 percent respondents have viewed that dwelling place related conditions is not secured because of the structural condition. At present, fishing community are facing huge problems regarding the dwelling place related matter. As a result, it has been considered as connected with social problems in the respective community. One of the key informants has expressed that the dwelling situations of the fishing community are not good because of their income level and source of income. He further informed that they live in 
vulnerable, unhealthy, unsecured, and fragile structure of dwelling for this reason.

Table 2.

Dwelling Place Related Problems

\begin{tabular}{lllll}
\hline Nature & Variables & Frequency & $\%$ & Total \\
\hline & Unhealthy & 17 & 5.92 & \\
Dwelling & Absence of Privacy & 25 & 8.71 & \\
Problems & Related Congestion & 94 & 32.75 & $100 \%$ \\
& Flimsy & 111 & 38.68 & \\
& Insecurity & 40 & 13.94 & \\
\hline
\end{tabular}

(Source: Field Survey, July-December, 2015)

\section{Social Capital}

Interpersonal relationship among the family members of the household is not excellent but in average. Most of the respondents (50.2\%) have stated that interpersonal relationship is good within the family and 37.3 percent of the respondents believe that the interpersonal relationship among the family members is neither good nor bad.

Trends of social relation depend on social values, customs, beliefs, rituals, prejudice, superstition, and culture. In this segment, data displays the trends of social relation within the fishing community. About half of the respondents $(47.7 \%)$ have opined that the trends of social relation are gradually decreasing. On the other hand, $24.7 \%$ of the interviewees have viewed that social relationship is rapidly decreasing. Thus, we learn about their views on social value, customs, brotherhood, and mentality of cooperation among the family members.

Cooperation is an important tool that influences the social environment of the community. About half of the respondents $(44.6 \%)$ believe that the state of cooperation among the community members is gradually declining, which demonstrates a negative sign for this area. Only 13.6 percent of the respondents have opined that the co-operational state of the haor region is stagnant.

In Hakaluki Haor, different types of social associations are in play. From the study, it was found that 72.1 percent of the social associations are 
dominated by the fishing community. Only 2.1 percent of the associations have performed to address economy-related issues. They are dominated and retained by influential people.

\section{Physical Capital}

In the present study, it has been found that more than half of the toilets $(51.2 \%)$ are made by ring slab and kutcha type toilets are found in 26.1 percent of the families. Few numbers of sanitary toilets are available in the study area. The data above clearly show the sanitation status of the fishing community in the haor region.

Place of birth is an essential phenomenon to realize the physical capital of the respondents' household in the study area. The researcher has closely surveyed and observed the situation of birthplace. Highest number of deliveries have happened in respondents' houses, which is 92 percent of the total interviewees. Only 4.9 percent of the deliveries have been done in government hospital.

The study elucidates the physical atmosphere of the dwelling condition. It has been observed that kutcha type of houses is more than half $(64 \%)$ and pucca house is not commonly available in the haor region. Only 4 percent of the houses in fishing community have been found to be pucca houses. Hence, data clearly demonstrates the status of physical capitals among the respondents' household.

Most of the households have received health-related treatment from the village doctors. Only few respondents have experience at government health facilities. Lack of motivation, insufficient health personnel, distance of health centers, scarcity of health centers, as well as superstition, belief and stereotype are the major barriers to preferring to receive service from the health facilities in the haor region.

Based on land ownership, the household land is classified into three categories: homestead land, agricultural land, and low land. The highest numbers of respondents $(51.9 \%)$ have homestead land in between the ranges of 0-24 decimal. At the same time, 74.2 percent of the households have 0-49 decimal low land. Only 2.8 percent of the respondents have agricultural land under the range of 100-149 decimal.

Different types of fishing gears have been found in the haor water body. In this segment, the researcher has accumulated the opinions of the fishing community and took notes about his observation. It has been found that five types of fishing gears were used in Hakaluki Haor: Current jal, 
Berjal, Thelajal, Jhankijal and Dharmajal. Almost all of them are very common and popular among the fishing community for fishing.

Marketing channel is an important component to analyze the physical capital of the fishing community. It has been found that half of the fishing community (50\%) sell their fish to the mahajan, 29.55 percent of the respondents sell their fish to the retailer and only one fifth of the total respondents sell their fish to the local general consumer.

\section{Financial Capital}

Fishing community of Hakaluki Haor depend on fish resources because of their subsistence. Data show that 43.6 percent of the respondents have stated that fish resources are rapidly declining from the water body because of mismanagement. Only 16 percent of the respondents have opined that fish resources are stagnant. For this reason, the source of the income from the fishing sector is gradually declining and plays direct impact on fishing community livelihood. All the information implies that the fishermen are not the hard-core poor compared with income per household TK. 9,648 in rural area of Bangladesh. (BBS,2010:28)

Monthly income of the fishing community is different because of their involvement. The average monthly income is only 8,021.34 Bangladeshi Taka (BDT). Most of the respondents' monthly income is between the ranges of BDT 4,001 and 8,000. In addition, 31.0 percent of the respondents earn under the range of BDT 8,001 to 1,2000.

From the study, it has been found that most of the fishing community borrowed money from non-government organizations and only 5.23 percent borrowed money from the bank. More than one fifth of the total respondents borrowed from their neighbors. Hence, it can be assumed that respondents are living in poverty.

Most of the fishing community in Hakaluki Haor region are directly involved in fishing for their income and subsistence. Fishing is the default profession. Seasonal variation, scarcity of fish species, food insecurity and present leasing procedure are not fully favorable to the fishing community. For this reason, some fishing community are involved in various activities

${ }^{4}$ Bangladesh Bureau of Statistics 
like agriculture, duck rearing, cattle, and buffalo rearing, daily labor and business. In this sub-section, it has been categorically displayed.

Table 3.

Secondary Options of Income

\begin{tabular}{llllc}
\hline Category & Variable & Frequency & $\%$ & Total \\
\hline \multirow{5}{*}{ Secondary } & Agriculture & 88 & 40.00 & $\Xi$ \\
Options & Duck Rearing & 28 & 12.73 & $\stackrel{8}{\circ}$ \\
& Cattle and Buffalo Rearing & 20 & 9.09 & \\
& Day Labor & 71 & 32.27 & \\
& Business & 5 & 2.27 & \\
& Remittance & 3 & 1.36 & \\
& Others & 5 & 2.27 & \\
\hline
\end{tabular}

Source: Field Survey (July-December, 2015)

Data allows a comparison between two seasons in terms of fishing in the haor water body. It has been found that most of the fishing community have opined that fishing is easier in the rainy season than other seasons. On the other hand, the respondents have opined that fishing is difficult in winter due to the decrease of water level and faulty leasing.

\section{Natural Capital}

Water bodies of the haor region are full of natural resources. The researcher has accumulated the opinions of fishing community and noted down his own observation. From the study, it has been found that many types of resources in the haor basin are medicinal plants and aquatic trees. Most of the respondents believe that Bisakhathali and Kukra are antibacterial items and water lilies which are used as medication for heart diseases. Besides, Hijal, Karac and Barun are the aquatic trees of the study area.

Environmental change is an essential event to realize to understand the natural capital of the respondents' household in the study area. From the study, it has been found that 36.24 percent of the respondents have opined that flash flood is the severe natural disaster in the haor region. On the other hand, imbalanced temperature and scarcity of fish species also have negative impact on the fishing community.

Fuel is one of the key items of the natural capital. It has been found that more than one fifth of the total respondents use straw as fuel while 20.91 percent of the households use trees. Hence, it can be said that respondents face homestead fuel scarcity. 


\section{DISCUSSION AND CONCLUSION}

Present status of the haor fishing community in Hakaluki is not satisfactory. The education level of the haor people is low in comparison with the national statistics. They are facing many challenges in terms of health facilities, housing patterns, sanitation, and state of family planning. However, astonishingly, the condition of drinking water is significantly good. In this section, the researcher points out that government and nongovernment initiatives should be taken for the fulfillment of their needs and expectation with special concentration, so that the situation in the haor basin would be developed gradually.

In this study, the researcher has found some key problems regarding the educational opportunities and facilities. A large number of the respondents (43.21\%) believe that the absence of financial ability is the key problem to receive education. Lack of proper motivation, long distance and shortage of educational institutions are the major barriers to receiving proper education in the fishing community.

Data also sheds light on the problems with accessing health services. Folk medicine is the key factor that decreases the preference for health service programs provided by the government and non-governmental organizations in the haor region. Long distance of medical centers, lack of information, shortage of medical doctors as well as social beliefs, rituals and customs are the barriers to easy access to the health services.

From the study, it has been found that many fishing communities $(34.49 \%)$ believe that overfishing is the major problem about growth and development of the fish species in the haor water body. It plays a negative role on the bread and butter of the fishing community. Indigenous fish fishing and hybrid fish culture are the significant components of the life and livelihood of the household respondents.

In this sub-section, the researcher has discussed the problems regarding the mismanagement of leasing systems in water body, which are creating obstacles of fishing community's livelihood. More than half of the respondents $(56.79 \%)$ believe that mismanagement of the present leasing system has reduced the opportunities of free access to fishing in the water body. The value of labor and job insecurity are also associated with the leasing system.

Haor water body is the habitat for local fish species. Artisanal fishing community are fishing in the water body to earn their lives. However, their recent experiences are not good about the fishing ground. About 26.83 percent of the respondents think that fake fishing community associations play very important role on leasing in water body. For this 
reason, fishing community have a bitter experience about leasing. It can be claimed that they are marginalized in the fishing ground due to their professional status.

In this segment, the researcher has discussed the impact of the present leasing system on artisanal fishing community and elite people of the society. 42.9 percent of the respondent believe that the artisanal fishing community are losing financially in the present leasing system. More than half of the interviewees $(57.8 \%)$ think that the elite group in the respective area are benefited and have more power than the artisanal fishing community.

In respect to the experience about accessing to loans, the data demonstrates a comparison between governmental and non-governmental credit initiatives which are started for the progress of fishing community livelihood in the haor region. It has been exposed that 34.1 percent of the respondents have stated that loan access to government organization is very difficult. 55.7 percent of the interviewees think that access to loans through non-government organizations is easy. Hence, it can be said that respondents are experienced in accessing the loans from government and the non-government organizations.

\section{IMPLICATIONS}

Numerous suggestions and recommendations are made based on the results of the study. Central recommendations are highlighted below.

$\Rightarrow$ Artisanal fishing community should be included and emphasized in policy, plan, strategy paper and annual allocation, which could improve the socio-economic status of the fishing community.

$\Rightarrow$ Motivational programs should be implemented for family planning, food habit, sanitation, and marital age of the households.

$\Rightarrow$ Government and non-government initiatives should be taken for training and creating alternative employment opportunities for the fishing-based community in haor region of Bangladesh.

\section{REFERENCES}

Ali, M. M., Belal Hossain, M., Minar, M. H., Rahman, S., \& Shafiqul Islam, M. (2014). Socio-economic aspects of the fishing community of Lohalia River, Bangladesh. Middle-East Journal of Scientific Research, 19(2), 191-195. http://doi.org/10.5829/idosi.mejsr.2014.19.2.8235

Bangladesh Bureau of Statistics (2010). Report of the Household Income and Expenditure Survey 2010. http://data.bbs.gov.bd/index.php/catalog/67

Deb, A. K. (2009). "Voices of the Fishantry": Learning on the livelihood dynamics from Bangladesh (Publication No. 24140) [Doctoral 
dissertation, University of Manitoba]. FGS Electronic Theses \& Dissertations.

Gill, G. J., \& Motahar, S. A. (1982). Social factors affecting prospects for intensified fish farming in Bangladesh. The Bangladesh Journal of Agricultural

Economics,

$5(1-2), 1-24$

http://doi.org/10.22004/ag.econ.212396

International Union for Conservation of Nature. (2006). Natural Resource Economic Evaluation of Hakaluki Haor, Bangladesh. Dhaka: IUCN Bangladesh.

Islam, M., Saha, N., \& Rahman, M. (2011). Economic activities decrease biodiversity in Hakaluki haor, the largest inland fresh water ecosystem in Bangladesh. International Journal of Environmental Sciences, 2(2), 946956.

Islam, S. (Ed). (2012) Banglapedia: National Encyclopedia of Bangladesh $\left(2^{\text {nd }} e d\right)$. Asiatic Society of Bangladesh.

Sultana, P., \& Thompson, P. M. (2007). Community based fisheries management and fisher livelihoods: Bangladesh case studies. Human Ecology, 35(5), 527-546. https://doi.org/10.1007/s10745-006-9092-3

Uddin M. J., Mohiuddin A. S. M., Hossain, S.T. \& Hakim, A. (2013). Ecoenvironmental Changes of Wetland Resources of Hakaluki haor in Bangladesh Using GIS Technology. Journal of Biodiversity \& Endanger Species, 1:1 DOI: 10.4172/2332-2543.1000103

Yeasmin, L. (2012). Role of Green Micro-credit is creating livelihood options and Women's Empowerment in a Bangladesh wetland [Master's thesis, University of Manitoba], umanitoba.ca

MOHAMMAD ALI OAKKAS, PhD, is an Associate Professor in Social Work, Shahjalal University of Science \& Technology, Sylhet-3114, Bangladesh. His major research interests lie in the field of Wetland management, Haor people, Ethnicity, NGOs Initiatives for social development, Food security and Gender Issues of Bangladesh. Email: alioakkas@gmail.com

MD. FAKRUL ISLAM, PhD, is a Professor in Social Work, University of Rajshahi, Bangladesh. His major research interests lie in the field of Socioeconomic policy, Water use and poverty reduction, Public health, Aged welfare, Micro-finance and rural development, and Regional social policy. Email:fakrul@ru.ac.bd

Manuscript submitted: July 23, 2020

Manuscript revised: November 4, 2020 Accepted for publication: December 8, 2020 